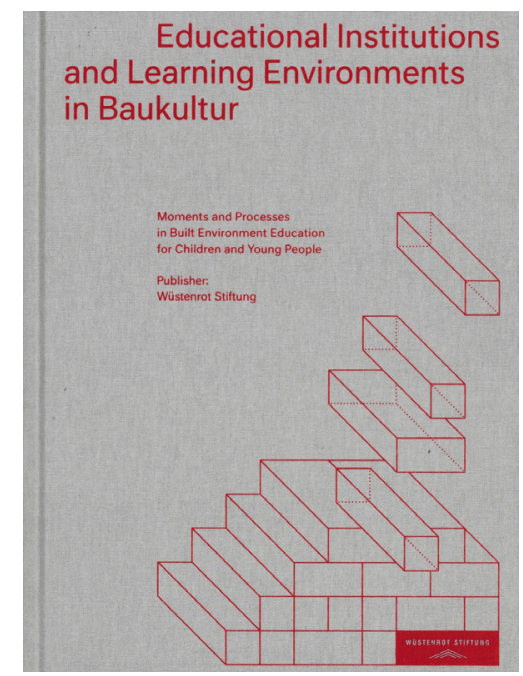

Educational Institutions and Learning Environments in Baukultur

Angela Million, Thomas Coelen, Felix Bentlin, Sarah Klepp, Christine Zinke

Año: 2019 Lugar: Reutlingen

Editorial: Fundación Wüstenrot (Wüstenrot Stiftung)

Páginas: 224

ISBN: 978-3-96075-009-3

\title{
Instituciones educativas y entornos de aprendizaje en Baukultur
}

El título completo del libro lo podemos traducir como "Instituciones educativas y entornos de aprendizaje en Baukultur. Momentos y procesos en la educación ambiental construida para niños y jóvenes". Baukultur se ocupa del diseño, planificación y co-construcción de nuestro entorno. Es, cada vez más, objeto de diversos programas de aprendizaje para niños y jóvenes. Por primera vez, este estudio explora cómo los jóvenes perciben estos programas y los incorporan a su vida cotidiana. Además, se estudia cómo asimilan importantes experiencias biográficas y decisiones relacionadas con Baukultur a diario, no solo remodelando sus propias cuatro paredes, sino también mientras viajan y en el universo online (Huerta, 2020).

¿Qué correlaciones existen entre biografías y educación ambiental construida? ¿Dónde podemos encontrar puntos de referencia para educadores y profesionales de los campos de la arquitectura, la planificación y el arte, en su trabajo con los jóvenes? ¿Cómo puede la educación hoy y en el futuro fomentar la participación en la configuración del entorno construido? Al utilizar una combinación de métodos visuales y narrativos, los autores del volumen logran presentar una biografía completa de experiencias relacionadas con el entorno construido (Huerta, 2019). Más allá de las formas de pensar predominantes, los niños y los jóvenes brindan nuevos conocimientos sobre las instituciones educativas y los entornos de aprendizaje en Baukultur.

El desarrollo a través de técnicas de construcción de lugares, relacionados con el concepto de baukultur, muy influido por el diseño de exteriores e interiores, se evalúa utilizando la calidad de vida, el desarrollo económico y la diversificación económica como marcadores. La calidad de vida y la calidad del lugar están intrínsecamente conectadas al atraer negocios, aumentar el empleo, mejorar la vida de las personas y potenciar los recursos creativos. Con el propósito de ayudar a comprender estos 
conceptos a los planificadores de programas y políticas, en el libro se exploran ejemplos exitosos de desarrollo de entornos que involucran creación y construcción de lugares orientados a la cultura, el arte y la educación (Huerta, Alonso-Sanz y Ramon, 2018). Se analiza cómo aplicar los conceptos aprendidos para generar una estrategia de desarrollo impulsada por la cultura, la arquitectura y el arte.

La asignación de recursos que supongan avances culturales y educativos de una región, puede mejorar su potencial como entorno favorable a las relaciones humanas. La educación y la cultura son componentes esenciales de la habitabilidad de un área, y se pueden utilizar para mejorar la convivencia, así como para, principalmente, fomentar el atractivo a sus residentes, desarrollando procesos y acciones culturales y educativas (Huerta y Alonso-Sanz, 2017). Además, los activos culturales y recreativos pueden posteriormente capitalizarse hacia diferentes tipos de desarrollo urbano, turístico, académico, e incluso logístico. Todo ello sin olvidar las cuestiones de género y las tendencias inclusivas en educación (Alonso-Sanz, 2017). Por ejemplo, las comunidades que mejoran su entorno construido con elementos formales y funcionales son más atractivas quienes las usan, y las disfrutan. Es importante atraer distintos tipos de públicos, que pueden actuar como impulsores económicos, culturales y sociales sustanciales, a través de lo que se conoce como "efecto multiplicador".

En el libro encontramos numerosas experiencias en diferentes entornos analizados en distintas ciudades alemanas. La práctica educativa se estudia, en este caso, mediante las entrevistas a participantes, tanto jóvenes como adultos y personas mayores. También se incide en la actual predominancia de los medios para aprovecharlos como empuje educativo. Se habla incluso, en uno de los apartados, del concepto de "familia como entorno educativo". La capacidad de construir, e incluso de influir en lo que serán las futuras construcciones, es una cualidad que debemos fomentar entre toda la población. En realidad, es así como se construye la ciudadanía.

El libro es muy atractivo, y combina imágenes de ejemplos acompañadas por ilustraciones representativas, de modo que la parte visual encaja con los textos en los que se van desgranando cada una de las cuestiones planteadas. A destacar también la apuesta por la investigación, algo que caracteriza al conjunto de autores y autoras que han realizado el volumen. La construcción de entornos educativos es un tema pendiente (Raedó y Atrio, 2018), y debemos insistir en mejorar en este aspecto, especialmente desde nuestra condición de docentes implicados.

\section{Referencias}

Alonso-Sanz, A. (2017). Repensando tres entornos educativos consolidados, Artseduca, 18, 79-99. 
Huerta, R. (2019). Diseño de espacios educativos para erradicar la exclusión, el machismo y la lgtbfobia. Tarbiya, Revista de Investigación e Innovación Educativa, 47, 93-106. DOI: https://doi.org/10.15366/tarbiya2019.47.007

Huerta, R. (2020). Arte, género y diseño en educación digital. Valencia: Tirant lo Blanch.

Huerta, R. y Alonso-Sanz, A. [eds.] (2017). Entornos informales para educar en artes. Valencia: PUV.

Huerta, R., Alonso-Sanz, A. y Ramon, R. [eds.] (2018). Investigar y educar en diseño. Valencia: Tirant lo Blanch.

Raedó, J. y Atrio, S. (2018). Arquitectura inclusiva y su utilización como instrumento socializador en educación. Tarbiya, Revista de Investigación e Innovación Educativa, 46, 41-54. DOI: https://doi.org/10.15366/tarbiya2018.46.03

Ricard Huerta. Universitat de València 